\title{
Legalidade, legitimidade e a derrocada do liberalismo clássico
}

\section{Legality, legitimacy and the collapse of classical}

\author{
liberalism
}

\section{Raphael de Oliveira Soares ${ }^{1}$}

\section{Resumo}

Esse texto busca esboçar um diálogo entre o pensamento político do jurista Alemão Carl Schmitt, principalmente no seu texto clássico "o conceito do político", e a sociologia do Estado de Max Weber. Segundo G.L.Ulmen (1985), a relação entre os dois autores representa menos uma relação de influencia ou descontinuidade do que uma transição de um período histórico para outro, de uma geração para outra, sendo ambos figuras representativas do pensamento político de sua época."Enquanto a geração de Weber ainda considerava 'a regra', a norma, a geração de Schmitt não o podia" (Ulmen, 1985). O que será proposto, ao longo do texto, será o mapeamento das linhas centrais do pensamento político dos dois autores, principalmente em suas

\footnotetext{
${ }^{1}$ Mestrando do Programa de Pós-graduação em Sociologia Politica da Universidade Estadual do Norte Fluminense Darcy Ribeiro. Bacharel em Ciências Sociais pela mesma instituição. Email: raphaeldeoliveirasoares@hotmail.com
}

Revista Cadernos de Estudos Sociais e Políticos, v. 5, n. 9, jan-junho 2016 
relações com as noções do que é "legal" e o do que é "legitimo", tentando, com isso, traçar algumas características históricas mais gerais, que denotam o fim de um mundo centrado na economia para um mundo em que a ação política é a protagonista, i.e.,a crise do liberalismo do século XIX, e de suas garantias constitucionais, e a emergência de um novo paradigma de exercício do poder político, muitas vezes associado a um "estado de exceção".

Palavras-chave: Carl Schmitt, Max Weber, liberalismo, discricionariedade.

\begin{abstract}
This essay seeks to sketch a dialogue between the political thought of the German jurist Carl Schmitt, mainly in his classical text "The concept of the political", and the Max Weber's sociology of the state. According to G.L.Ulmen (1985), the relation between these two theorists represents less a rupture or continuity than a historical transition, being the both of them representative members of the political thought of their epoch. "While Weber's generation would still consider 'the rule', the norm, Schmitt's generation could not" (Ulmen, 1985). What is intended, along the text, is to analyze the main points of the political thought of these two authors, most of all in their relations with the ideas of what is "legal" and what is "legitimate", trying to trace out some general historical trends, which denote the end of an economically centered world and the beginning of a world in which the political action has taken the protagonist role.
\end{abstract}

Keywords: Carl Schmitt, Max Weber, liberalism, discretionary power. 


\section{Contradições de um mundo economicamente centrado}

O célebre ensaio "O conceito do político", de Carl Schmitt, é uma obra da década de 1930, período histórico que se tornou notório pelo esfacelamento dos princípios liberais, cuja expressão mais dramática, na Europa, pode ser facilmente identificada, em seu princípio, na primeira guerra mundial. Tal conjuntura histórica abriu espaço, de vez, para o protagonismo de novos modelos de organização do Estado, da sociedade e da economia. Seja a emergência de um Estado social, de um welfare state, nos países europeus que se mantiveram democráticos, que incorporaram as organizações trabalhistas em sua estrutura política, cedendo ao inevitável reformismo social, seja a aparição do fascismo e do bolchevismo, nos países que abandonaram os princípios constitucionais da democracia liberal burguesa, o paradigma liberal clássico, de uma sociedade estruturada em torno de um mercado autorregulável, tendo como premissa ideológica o repudio de qualquer intervenção estatal e social no "natural" jogo das forças de mercado, não era mais sustentável em face de uma nova situação histórica que se lhe apresentou.

Como nos mostrou a antropologia econômica de Karl Polanyi (2000), a estruturação das sociedades do oeste europeu do século XIX, centrada em um mercado autorregulável, imune às intervenções, repousava sobre premissas fragilíssimas, levando-se em conta seu caráter altamente artificial, antinatural. Nesse sentido, nota-se que o mercado, lugar de encontro entre vendedores e compradores, é uma instituição que existiu em diversas civilizações, nos mais distintos períodos históricos. No entanto, a organização da vida econômica e social da sociedade ser centrada nos processos de troca, realizados nesses mercados, é algo historicamente inédito. Os estudos antropológicos nos mostram que, em grande parte das sociedades

Revista Cadernos de Estudos Sociais e Políticos, v. 5, n. 9, jan-junho 2016 
tradicionais, a produção e a distribuição dos bens materiais, produzidos pela comunidade, operavam segundo a lógica das obrigações sociais, tradicionalmente fixadas entre os agrupamentos parentais. Ainda não se produziam mercadorias, feitas para obterem o maior lucro possível no mercado. O preço ainda não havia se tornado o grande norte pelo qual se guiaria a produção social. A produção tinha por intuito a celebração das redes de afinidades e da destreza do produtor, e os objetos que faziam parte dos intercâmbios, com efeito, tinham antes um valor simbólico e moral do que um valor monetário. Por conseguinte, o homem ainda não precisava vender os frutos de seu trabalho, ou mesmo de sua força de trabalho, para subsistir. Sua sobrevivência independia de seu valor de mercado, do que ele conseguia comprar ou vender. Ele estava, poder-se-ia dizer, naturalmente protegido pelas solidariedades tradicionais.

A primazia adquirida pelo mercado, na estrutura das sociedades, deve-se, em grande parte, ao otimismo do século XVIII em relação às perspectivas econômicas que se lhe abriam, fruto dos progressos materiais promovidos pelo capitalismo comercial e pela expansão marítima. Para os economistas liberais, o mercado, ao despir-se de todos os monopólios mercantis que o antigo regime havia lhe imposto, seria o local onde os indivíduos exerceriam sua liberdade e se autorrealizariam, libertando-se das inibições e privilégios decorrentes das anacrônicas instituições do antigo regime, promovendo, assim, o desenvolvimento de suas potencialidades e a realização do ideal meritocrático burguês. As instituições políticas tradicionais do antigo regime europeu, e todos seus encargos sobre a atividade econômica, por sua vez, eram vistas como o fardo que impediria os indivíduos de alcançar o ponto máximo ao qual o seu talento e os frutos de seu trabalho lhes podiam levar, 
tendo em vista que a nobreza e o clero se apropriavam de parcelas consideráveis do que era produzido.

A perda de legitimidade dessas instituições sociais e políticas, com efeito, moldou a visão antropológica da emergente classe burguesa e de seus teóricos. Os autores liberais clássicos da economia, como Adam Smith, adotaram uma perspectiva atomista do ser humano, na qual os indivíduos realizavam a sua socialização através do mercado, dos atos de comprar e vender de suas atividades econômicas. $\mathrm{O}$ indivíduo era o dado primeiro. A socialização não lhe seria natural, algo congênito a sua condição humana, como diria Aristóteles, a socialização ocorreria num momento posterior à produção de sua atividade econômica, ou em sua realização, como algo artificial, fruto de um ato pragmático da razão. A filosofia burguesa, dessa forma, separa, ontologicamente, o indivíduo da coletividade. Os regimes constitucionais, culminância das revoluções burguesas, com efeito, denotam, claramente, que a intenção precípua de suas formulações era a de proteger os indivíduos, a sociedade civil, da ação potencialmente discricionária que as instituições tradicionais do antigo regime, o poder político à época, frequentemente incorriam, lhes impedindo de ser quem potencialmente poderiam ser. "Laissez-faire, Laissez-passer", a fórmula clássica do período.

No entanto, as intempéries pelas quais o capitalismo e sua ideologia passaram na primeira metade do século XX mostraram, de forma crua e direta, que uma sociedade estruturada em torno do mercado, tendo por princípios o individualismo filosófico e a acumulação privada, corre o risco de deixar de ser uma sociedade. O mercado não está preocupado com a preservação do ambiente natural do ser humano, no qual viveu seus antepassados e no qual viverá as gerações vindouras; o mercado não está preocupado com a devastação que a nova estrutura econômica impinge ao 
ambiente cultural dos trabalhadores, potencialmente degradados pela nova condição. As catástrofes sociais e naturais com as quais se depararam os personagens da época, e com as quais ainda nos deparamos, tornaram claro que uma separação entre a economia e a atividade política normativa de uma sociedade, que deixa, ao livre jogo dos preços, da oferta e da procura, o destino do homem e da natureza, em um mundo de superpotências econômicas, é a receita para o genocídio.

De acordo com Robert Castel (2012), a sociedade liberal europeia do século XIX só não entrou em colapso, decorrente da avassaladora transformação social advinda da reestruturação econômica pela qual passou, porque havia um "reservatório" de vínculos tradicionais, que mitigavam o estatuto de mercadoria que o trabalhador havia adquirido na nova ordem social. A obra de Émile Durkheim (2010) e de toda a sociologia da época aparecerá como um grande instrumental de oposição à perspectiva economicista e individualista da sociedade, propondo uma visão "sociológica da sociedade", o que pareceria um paradoxo caso não tivéssemos em mente a concepção liberal do homem e da sociedade, na qual o ultimo termo é rebaixada para a condição de meio de promoção das potencialidades e das volatilidades do primeiro termo, subordinando-se a ele.

\section{A inexorabilidade da ação política}

Segundo Castelo Branco (2005), o pensamento de Carl Schmitt se construiu justamente em torno de sua polemica com o pensamento liberal, principalmente contra o quadro inverossímil pintado por sua vertente da filosofia da história e com o ímpeto com o qual essa se lançou ao "esvaziamento" do poder político. A história como teleologia é uma marca Revista Cadernos de Estudos Sociais e Políticos, v. 5, n. 9, jan-junho 2016 
do pensamento do século XVIII e XIX. Sejam marxistas, positivistas, liberais, grande parte dos pensadores desse período interpretava a história como o desdobramento de um princípio imanente, ainda que cada um conferisse um telos especifico a essa progressão histórica. A corrente filosófica de cunho liberal tinha como postulado que o progresso material da sociedade acabaria com o conflito, superaria os antagonismos sociais prevalecentes nas formações históricas anteriores, instaurando a "Paz Kantiana". O progresso histórico da razão acabaria com os casos extremos de pauperismo e barbárie, pondo um termo à contingência e à eventualidade, eliminando a imprevisibilidade, a necessidade de tomar decisões capitais, i.e., com o que Carl Schmitt define como a "essência do político".

A “questão social” e as catástrofes representadas pelas guerras mundiais, não obstante, se colocaram como um questionamento histórico a tais fábulas de progresso material e moral. O mal-estar daquela civilização, a sensação de que havia, ali, um ambiente de promessas não cumpridas, foi algo central nas reflexões de mentes como a de Nietzsche e a de Freud. Assim, se os aspectos conflitivos, dramáticos, contingenciais e imprevisíveis da realidade histórica dos agrupamentos humanos não haviam desaparecido, a ação política, por sua vez, também não poderia deixar de existir. A política constitui a esfera da decisão sobre a realidade existencial, sobre aquilo que não está previsto na normatividade jurídica da sociedade e exige uma resposta imediata.

O ponto central da reflexão de Schmitt, em nosso entendimento, e que segue as proposições de Habermas, como exposto em seu prefácio a obra o "conceito do político", é que o autor se questiona acerca da essência do político como um filósofo tradicional, sob um viés epistemológico, não a associando, necessariamente, ao Estado. 
Nesse sentido, suas asserções se dirigem não só a considerações de natureza política e jurídica, mas, sobretudo, a considerações metafísicas, ontológicas. A metafísica moderna clássica havia transferido para o interior do indivíduo, para o cogito cartesiano, a função de ser a instancia última de decisão sobre a "essência" da realidade, enquanto a explicação dos aspectos sensíveis, concretos, da realidade histórica, foi relegada a uma posição periférica. Contra isso o jurista alemão se insurgiu. Para Schmitt, existia, na definição do que é "real", um aspecto objetivo que era irredutível a qualquer solução subjetivizante. Por haver, em toda situação concreta, uma indefinição latente que só poderia ser superada pela interferência de uma interpretação comunitária, i.e., uma instancia soberana que pudesse definir o indefinido, tal ordenação não poderia ser estabelecida no interior da cognição individual.

A "decisão política", no sentido em que é a mediação entre o "ser" e o "não ser", caracteriza-se, fundamentalmente, pela polemica. Os conceitos políticos, com efeito, denotam, claramente, o embate inerente a suas categorias e, principalmente, o embate pela interpretação substantiva de seus significados. "Democracia", "Justiça”, "Liberalismo", "Republica”, "Bem comum", etc., são todos conceitos que, ao mesmo tempo em que forjados por atores em luta, tendo em vista inimigos historicamente específicos, são conceitos relativamente vazios de significado concreto, i.e., são conceitos cuja significação especifica está aberta à interpretação dos diferentes agrupamentos políticos que se antagonizam. Assim, o elemento agonístico das definições conceituais se localiza muito além da uma definição lógica, formalista, se situando na irracionalidade dos conflitos humanos, na disputa pelo conteúdo especifico das palavras que dão sentido a experiência e norteiam a ação humana. Assim, eliminar o político, ou neutralizá-lo, como 
diria Schmitt, como foi intuito da perspectiva liberal, seria cercear a própria capacidade humana de identificar visões normativas divergentes.

Dessa forma, a geração de Carl Schmitt, como observou G.L.Ulmen (1985), se deparou com uma conjuntura histórica bem distinta daquela com a qual se desenvolveu a hegemonia do pensamento liberal, e, com efeito, não podia mais aceitar os pressupostos advogados por tal hegemonia ideológica. A sustentação de uma ordem fundada na autarquia do indivíduo, e os possíveis impactos deletérios que tal imagem de mundo poderia ter para a coletividade, tinha limites claros e, destarte, não poderiam ser ignorados por muito tempo. Assim, à crítica da metafísica do individualismo burguês se somará uma argumentação com desdobramentos políticos e jurídicos, que o debate entre dois paradigmas de exercício do poder, decisionistas e normativistas, teria a capacidade de refletir com acuidade, de modo a denotar tal transição mais ampla entre dois tempos históricos distintos, e os desafios teóricos propostos por essa transição. Nesse sentido, gostaria de chamar atenção sobre um ponto especifico dessa querela: a relação problemática entre legalidade e legitimidade.

Max Weber, um liberal, ao caracterizar o tipo de dominação política legitima presente em uma sociedade moderna, a dominação racional legal, que instrumentaliza seu domínio mediante um corpo de normas formuladas tecnicamente, associa a legalidade técnico-jurídica à legitimidade (ColliotThelene, 1999). A crítica da geração de Schmitt, com efeito, se dirigirá ao pensamento político de base jurídico racional, pondo em cheque, principalmente, a crença na legitimidade das normas prevalecentes na sociedade erigida pelo liberalismo burguês. Interessante notar, contudo, que o problema da relação entre discricionariedade e norma, entre contingência e regularidade, e dos problemas de legitimidade que lhes estão atrelados, é um 
problema antigo e fundamental na análise política e social. Tanto Locke, que legitimava o direito de rebelião contra aqueles que usurpavam do poder que lhes fora atribuído, quanto Rousseau, que dizia que qualquer lei que não expressasse a "vontade geral" e tivesse como objeto de sua ação um indivíduo genérico, abstrato, seria considerada imoral, portanto ilegítima, se colocaram a perene questão: quem controla o controlador? E, principalmente, sobre o que se fundamenta a legitimidade das prescrições jurídicas emitidas pelas instituições do Estado ou, ao contrário, em que medida uma ação discricionária se torna legitima?

Para Rousseau, a legitimação da lei se dava pelo fato da mesma ter sido fruto de um processo de deliberação e participação coletivas, que se dava mediante o concurso direto de todos os cidadãos, atestando, assim, seu caráter geral, portador de um bem coletivo e de uma universalidade abstrata. A democracia direta, contando com a participação de todos, era o fundamento da legitimidade. $\mathrm{O}$ cerne do republicanismo consiste, justamente, na ideia de que esse é um regime estruturado por leis, onde todos, incluindo os que estão investidos em posição de mando, estão submetidos à propalada generalidade da norma. A eliminação da existência de um poder discricionário, não sujeito a normas, com efeito, foi o alvo contra o qual se armou a teoria republicana. A vinculação do poder à norma, a necessária referência à lei, nesse sentido, é um ponto comum tanto na abordagem republicana quanto liberal do poder, se apresentando como uma justificação moral necessária para a atividade coercitiva do Estado. Nesse sentido, nos remetemos à proposição de Herman Heller (1979), segundo a qual o Direito, em sua acepção liberal, é a manifestação eticamente necessária do Estado, ou seja, todo poder político seria poder juridicamente organizado. 
Todavia, tais concepções idílicas da vontade geral, supostamente portadora de uma universalidade abstrata, traziam consigo o perigo de engendrar um processo de fetichização das leis, i.e., a estrutura jurídica de uma dada sociedade vista como algo natural, dada, não vista como fruto da ação humana e, por isso, passível de crítica. Tal naturalização, por sua vez, vem sendo alvo de múltiplas contestações, cujo objetivo é chamar atenção para o Estado, sobretudo, como um lugar de construção do seu próprio significado. Uma máquina cultural que exerce violência, sobretudo simbólica, ao aparecer como unidade promotora do bem comum, quando, na verdade $\mathrm{e}$ frequentemente ao longo da história, se apresentou como um instrumento de manutenção das posições e privilégios de uma minoria. Nesse sentido, o questionamento da real universalidade das leis se faz de extrema relevância e importância, e a suposta imparcialidade da tecnicidade normativa dos ordenamentos jurídicos, mediante os quais o Estado justifica sua ação, é problematizada sob o prisma da sua possível ausência de legitimidade, tendo em vista a possibilidade de sua autointitulação da imparcialidade e representatividade do bem comum ser, de fato, um engodo.

Apresentar que as leis imperam é mascarar o simples fato que agrupamentos humanos, dotados de interesses particulares, dominam outros agrupamentos humanos. A tão glorificada ideia da vigência de um "Estado de direito" nada mais é do que a vigência de um direito privado, que, obviamente, só favorece aqueles que têm interesse na manutenção do status quo. Para Herman Heller, "A amoralização do direito leva à glorificação religiosa da situação real de poder”. Esse trecho do texto de Carl Schmitt também lança uma boa luz sobre a questão:

(...) se "direito", aqui, designa as leis positivas e métodos de legislação existentes que devem continuar 
a ser aplicados, pois, dessa feita, o "domínio do direito" nada mais significa do que a legitimação de um determinado status quo, em cuja manutenção tem, naturalmente, interesse todos cujo poder político ou vantagem econômica se estabiliza nesse direito (Schmitt, 2008, p.72).

Nesse sentido, o que a teoria jurídico-política de Carl Schmitt postula é a primazia das relações de força existentes na sociedade sobre os ordenamentos jurídicos estabelecidos. Só há possibilidade de vigência de um determinado conjunto de normas jurídicas se as relações que esse Direito estabiliza se mantêm coesas ao longo do tempo. Se há uma ruptura na ordem social, i.e., se os segmentos que compõem as sociedades não mais interagem de forma harmônica, de modo que não exista um consenso mínimo, interclasses, sobre a existência de algum tipo de justiça social, que possa legitimar a distribuição desigual de bens materiais e simbólicos, então o "dever-ser", implícito em toda normatização, paira totalmente desconectado, defícitário em legitimidade e funcionalidade, sobre um "ser" marcado pela turbulência e indeterminação.

O Direito, em um sentido normativo, precisa ser visto sob o prisma de uma racionalidade comunicativa, não apenas instrumental. A crítica do republicano Habermas (2012), em suas considerações jurídicas, à construção intelectual Weberiana, se direciona no sentido de Max Weber não ter levado às últimas consequências as premissas de sua própria teoria, não vendo, no Direito, um locus de institucionalização de projetos normativos alternativos, para além de seu papel de institucionalizar uma racionalidade de tipo instrumental, técnico. Se Weber identificou, no processo de racionalização cultural, pelo qual passou o Ocidente, um processo de autonomização das distintas esferas de valor cultural, levando a fragmentação da razão, ele não 
teria terminado seu trabalho ao não investigar o modo como essas distintas modalidades de razão se institucionalizam, se objetivam, na realidade, i.e., ele teria negligenciado os modos de objetivação das racionalidades de tipo normativas e expressivas. Por isso, ao investigar as características do Estado moderno, ele o viu como uma instituição movida por uma racionalidade administrativa, análoga a existente no mercado, assentada numa visão tecnicista do Direito, que tinha por função primaz promover e viabilizar a burocratização do poder político.

No entanto, para Habermas, o Direito teria, como uma de suas funções elementares, a capacidade de preservar o mundo da vida, o mundo dos consensos tácitos, da inter-pessoalidade, dos imperativos de poder e acumulação dos sistemas político e econômico. A existência de uma esfera pública autônoma, nesse sentido, não impelida por imperativos de decisão, é o pré-requisito institucional para a vigência de uma racionalidade comunicativa, mediada pelo discurso, que busca testar e submeter a um exame crítico todas as normatizações e asserções, dos atores públicos, que se coloquem com pretensões de veracidade e de validade, e que tenham por objetivo transcender o momento particular, tendo vigência sobre o ordenamento mais geral da sociedade. Portanto, as ordenações jurídicas de uma sociedade não devem pairar no ar. O que é explicitado no Direito, como norma do agir, tem que mostrar sua validade, quando inquerido em processos públicos de deliberação.

Sem embargo, para além da especificidade e autonomia do Direito frente ao poder político, um questionamento que se mantém contemporâneo é aquele que se direciona, justamente, para o sentido oposto, ou seja, o de apontar para as limitações do Direito para o estabelecimento de um projeto de sociedade que possa se chamar de democrático, no sentido de que haja um mínimo 
aceitável de igualdade de oportunidades políticas e econômicas para todos os cidadãos. Desse modo, parece claro que, para que os indivíduos possam encontrar possibilidades de autodeterminação, i.e., para que eles possam alcançar aquilo que suas capacidades lhes permitem, é necessária uma intervenção estrutural na sociedade. Até o republicano Rousseau, avesso a intervenções, já havia alertado para a necessidade de certa igualdade material, que propiciasse autonomia para os indivíduos se expressarem politicamente. Para ele, era evidente que as bases econômicas, sociais e políticas de uma sociedade estavam interligadas. Todavia, isso foi contra o qual se forjaram todas as argumentações liberais, tentando evitar, a qualquer custo, o papel estruturante do poder público na sociedade civil.

A despeito dos elegantes argumentos liberais em prol de uma "despolitização" da sociedade e do livre jogo das forças "naturais" de mercado, a experiência histórica provou o quanto um poder privado, quando adquire um caráter monopolístico, pode ter uma influência indubitavelmente pública. A desregulação dos conglomerados capitalistas, respaldada em um direito privado, tem a capacidade de ser avassaladora e muito mais perniciosa a coletividade do que qualquer intervenção estatal. De acordo com as palavras de Franz Neumann, é historicamente impossível afirmar que, por si só e na generalidade dos casos, o intervencionismo do governo tenha diminuído a extensão da liberdade individual. Se atentarmos para o papel social que os Estados vêm desempenhando, regularmente, desde aproximadamente a década de 1930 do século passado, chegaríamos a conclusões opostas da ideia liberal do Estado. Franz Neumann (1979) cita um discurso proferido pelo ministro da corte suprema americana, Jackson, que ilustra bem a questão: 
A tarefa de traduzir as generalidades majestosas da carta de direitos, concebida como parte do padrão de Governo liberal no século XVIII, em restrições concretas nos tratos oficiais dos problemas do século $\mathrm{XX}$, é algo que perturba a autoconfiança. Esses princípios cresceram em solos que também produziram uma filosofia na qual o indivíduo era o centro da sociedade, em que sua liberdade era conseguida apenas devido à ausência de restrições governamentais... Devemos transplantar esses direitos para um solo em que o conceito de laissez-faire ou o princípio da não interferência diminui, pelo menos nos assuntos econômicos, e os avanços sociais são crescentemente buscados por meio da mais estreita integração da sociedade e fortalecimento dos controles governamentais.

Assim, a visão normativista, liberal, da ação política, que teria como proposição central a tese de ser a norma a única criadora do poder político, vai ser inapelavelmente confrontada pela experiência histórica que trouxe a "questão social", como degradação do ambiente cultural de inúmeras sociedades, da saúde física e mental de seus membros, e por duas guerras mundiais, somadas a várias outras intempéries de não menos importância, como acontecimentos impossíveis de serem manejados sob as formas jurídicas vigentes. Não atentar para o caráter criador de novos ordenamentos, intrínseco ao poder político, é uma grave negligencia por desconsiderar a instancia que tem a possibilidade de resolver os impasses históricos, i.e., o político. O que o pensamento liberal não observa é, assim, o inconteste caráter criador de direito que o poder político, de fato, possui. Para Carl Schmitt, não há norma onde predomina o caos. O poder político seria anterior 
a qualquer tipo de ordenação jurídica, tendo em vista ser a instancia com possibilidade de instaurar um ambiente estável para a vigência da normatividade. A inspiração hobbesiana, nesse ponto, se faz nítida. Não há direito no Estado de natureza, senão o do mais forte. Somente a partir da consolidação da unidade soberana, pacificada internamente, as ordenações normativas podem entrar em vigência. O Estado não só detém o monopólio da violência física, como o monopólio de tomar decisões capitais para a sobrevivência da coletividade.

Nesse sentido, a importância da liderança carismática, do líder messiânico, como elemento crucial da teoria Weberiana, se faz notar por ser o elemento teórico que lhe permite lidar, conceitualmente, com a excepcionalidade. Se os tipos de dominação tradicional e burocrática se caracterizam, cada uma com seu tipo específico de legitimação, pela perpetuação de um ordenamento, o elemento carismático da personalidade individual, por sua vez, é o que lhe possibilita a apreensão teórica da mudança. Nesse sentido, a existência de indivíduos, únicos em seus talentos, imbuídos de suas convicções, sendo capazes de angariar seguidores e romper com o caráter rotineiro de um estado de coisas, é crucial para o entendimento do papel da personalidade individual nos rumos da História.

Nesse sentido, percebe-se a genialidade de Max Weber, que, não obstante tenha sido um liberal, foi um cientista social no amplo sentido do termo, e suas posições teóricas, com efeito, se distanciam, e muitas vezes se opõem, aos reducionismos do liberalismo econômico clássico e de sua metafísica, assentada no homo economicus e articulada em torna da neutralização da esfera política através de proposições filosóficas e ordenamentos jurídicos. A História, no sentido de Weber, sendo um ambiente de cisão e disputas, no qual os agentes lutam para fazer prevalecer seus pontos de vista, seus valores, 
como modelos de ação a serem seguidos pelos demais, jamais pode prescindir da política, se tivermos em conta que essa é a esfera da atividade humana que tem a capacidade de identificar diferenças entre os diversos projetos normativos, entre as distintas normas de estruturação da realidade que se antagonizam, e, desse modo, decidir entre eles.

\section{Considerações finais}

Ao longo do texto, tentei explicitar a transição histórica e teórica entre a noção liberal de exercício do poder, que vê nas ordenações legais fontes inequívocas de legitimidade, sustentando que esse é o único tipo de ação possível aberta ao Estado, i.e., a ação mediada pelo Direito, em direção a visões que imputam ao Estado, ou a um líder carismático, capacidades intervencionistas e discricionárias, que, apoiadas no apoio popular ou no resultado efetivo e salutar de suas ações para o benefício coletivo, prescindiria da base jurídica e, mesmo, poderia the contrariar. Tal reconstrução não foi, de forma nenhuma, com intenção de endossar ou fazer uma crítica moral a qualquer uma das perspectivas. O que importa, a meu ver, é a necessidade de se manter, tanto quanto em considerações práticas quanto em teóricas, a flexibilidade em relação às contingências históricas e aos desafios conjunturais propostos pelos tempos. A representação da "vontade geral", do "bem comum", e a própria existência desses termos, é um terreno deveras sinuoso para não nos mantermos minimamente cautelosos. Da mesma forma que a questão problemática da justiça, que jamais deveria ser pensada descolada dos contextos históricos que lhe atribuem sentido. Todavia, conclui-se que, tanto a lei pode se tornar injusta, favorável aos interesses de minorias, em detrimento da maioria, quanto um 
Estado, ou o grupo que se apodera dele, imbuídos de suas "razões de Estado", pode se fazer portador, de fato, de interesses gerais, frente aos antagonismos prevalecentes na sociedade civil, i.e., pode exercer seu poder discricionário em ações que, indubitavelmente, beneficiam a coletividade. Se nos lembrarmos que foi sob Bismarck e Napoleão III que começou a se esboçar, na Europa, uma legislação que garantia a seguridade social dos trabalhadores, pode-se passar a ter um melhor juízo sobre regimes fortes e intervencionistas. 


\section{REFERÊNCIAS BIBLIOGRÁFICAS}

CASTEL, Robert. As metamorfoses da questão social: uma crônica do salário. Petrópolis: Vozes, 2012.

CASTELO BRANCO, Pedro H. Villas Bôas. "Liberalismo político no pensamento de Carl Schmitt: amigo ou inimigo?". Revista Brasileira de Ciências Sociais, vol. 20, n 59, 2005, pp.158-162.

COLLIOT-THELENE, Catherine. "Carl Schmitt versus Max Weber: juridical rationality and economic rationality". In: MOUFFE, Chantal (ed.), The challenge of Carl Schmitt. London/New York: Verso, 1999.

DURKHEIM, Émile. Da divisão do trabalho social. São Paulo: Martins Fontes, 2010.

FERREIRA, Bernardo. "Sujeito e ordem: romantismo e decisionismo no pensamento de Carl Schmitt". Dados - Revista de Ciências Sociais, vol. 45, $\mathrm{n}^{\circ} 4,2002$, pp. 599-648.

HABERMAS, Juergen. Teoria do agir comunicativo, 1: racionalidade da ação e racionalização social. São Paulo: Martins Fontes, 2012.

HELLER, Herman. "Teoria do Estado". In: CARDOSO, Fernando Henrique; ESTEVAM, Carlos (orgs.), Política e sociedade. Companhia Editora Nacional, 1979.

NEUMANN, Franz. "O conceito de liberdade jurídica". In: CARDOSO, Fernando Henrique; ESTEVAM, Carlos (orgs.), Politica e sociedade. Companhia Editora Nacional, 1979.

POLANYI, Karl. A grande transformação: as origens da nossa época. Rio de Janeiro: Elsevier, 2000.

SCHMITT, Carl. O conceito do político. Belo Horizonte: Del Rey, 2008.

ULMEN, G.L. "The sociology of the state: Carl Schmitt and Max Weber". State, Culture and Society, vol. 1, nº 2, 1985, pp. 3-57.

WEBER, Max. Economia e sociedade: fundamentos da sociologia compreensiva, Volumes 1 e 2. Brasília: Editora UnB, 2009. 
Recebido em: 19/01/2015

Aprovado em: 27/01/2016 